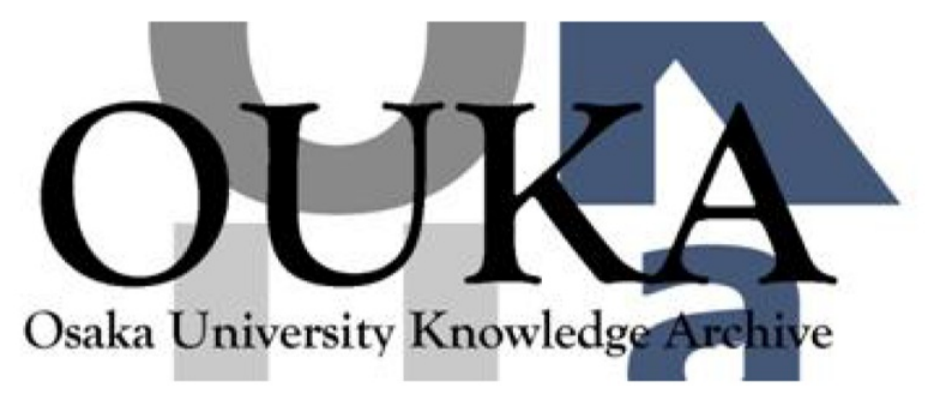

\begin{tabular}{|c|l|}
\hline Title & $\begin{array}{l}\text { Electromagnetically excited acoust ic resonance } \\
\text { for evaluating attenuation coefficient and } \\
\text { grain size in polycrystalline metals }\end{array}$ \\
\hline Author(s) & Hirao, M.; Ogi, H. \\
\hline Citation & Applied Physics Letters. 64(17) p. 2217-p. 2219 \\
\hline Issue Date & $1994-04-25$ \\
\hline oaire:version & VoR \\
\hline URL & https://hdl. handle. net/11094/3246 \\
\hline rights & \\
\hline Note & \\
\hline
\end{tabular}

Osaka University Knowledge Archive : OUKA

https://ir. Library. osaka-u. ac. jp/

Osaka University 


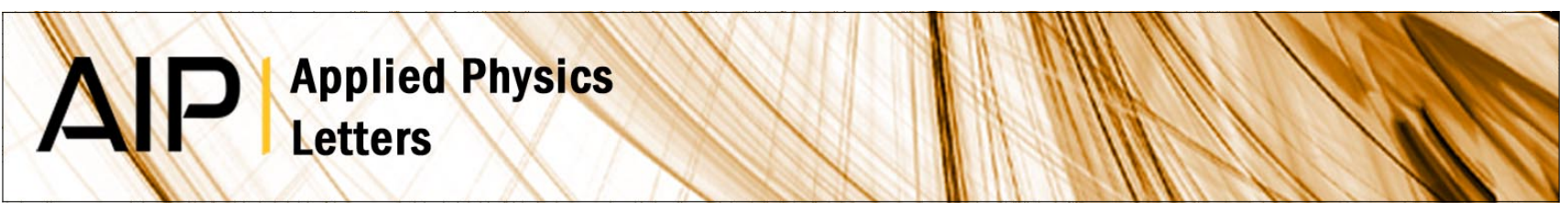

\section{Electromagnetically excited acoustic resonance for evaluating attenuation coefficient and grain size in polycrystalline metals}

M. Hirao and H. Ogi

Citation: Appl. Phys. Lett. 64, 2217 (1994); doi: 10.1063/1.111678

View online: http://dx.doi.org/10.1063/1.111678

View Table of Contents: http://apl.aip.org/resource/1/APPLAB/v64/i17

Published by the American Institute of Physics.

\section{Related Articles}

Vacancies, twins, and the thermal stability of ultrafine-grained copper Appl. Phys. Lett. 99, 231911 (2011)

Atom probe study of $\mathrm{Cu}$-poor to $\mathrm{Cu}$-rich transition during $\mathrm{Cu}(\mathrm{In}, \mathrm{Ga}) \mathrm{Se} 2$ growth Appl. Phys. Lett. 99, 232108 (2011)

Direct visualization and characterization of chemical bonding and phase composition of grain boundaries in polycrystalline diamond films by transmission electron microscopy and high resolution electron energy loss spectroscopy

Appl. Phys. Lett. 99, 201907 (2011)

Molecular dynamical investigation on dislocation near twist-grain boundary of Ni under compression J. Appl. Phys. 110, 094315 (2011)

Electrical conduction of intrinsic grain and grain boundary in Mn-Co-Ni-O thin film thermistors: Grain size influence

J. Appl. Phys. 110, 093708 (2011)

\section{Additional information on Appl. Phys. Lett.}

Journal Homepage: http://apl.aip.org/

Journal Information: http://apl.aip.org/about/about_the_journal

Top downloads: http://apl.aip.org/features/most_downloaded

Information for Authors: http://apl.aip.org/authors

\section{ADVERTISEMENT}

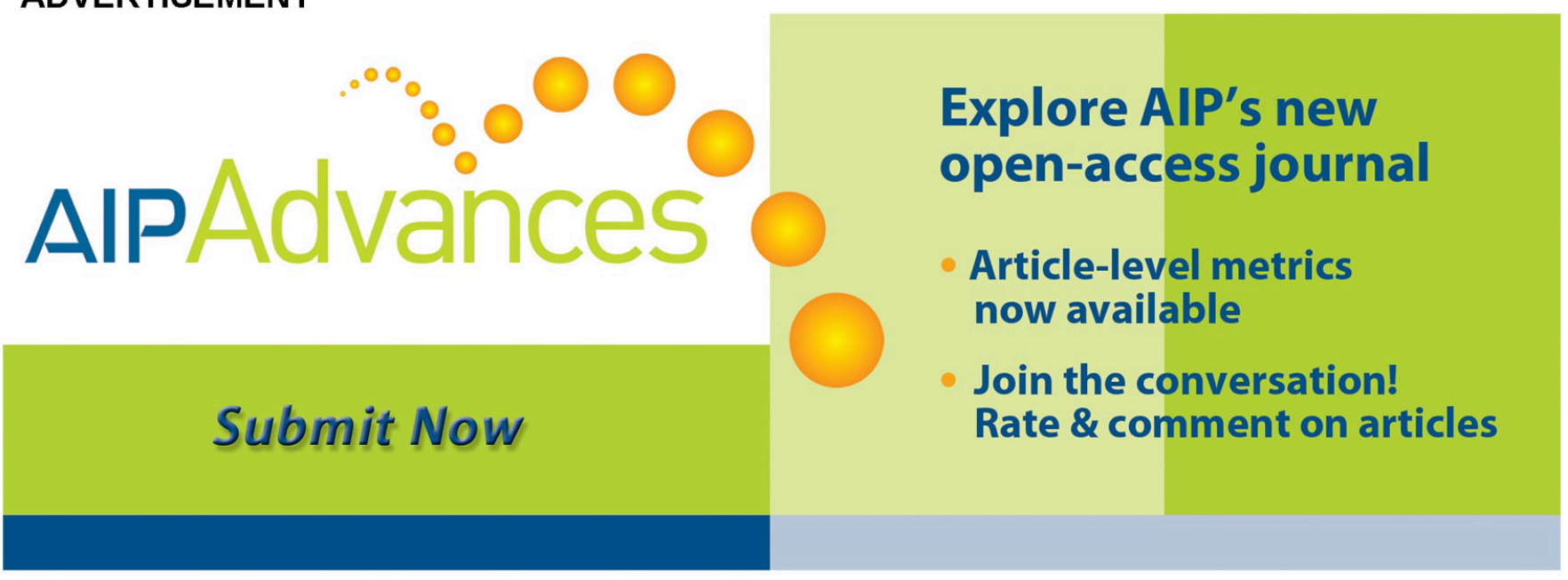




\title{
Electromagnetically excited acoustic resonance for evaluating attenuation coefficient and grain size in polycrystalline metals
}

\author{
M. Hirao and $\mathrm{H}$. Ogi \\ Faculty of Engineering Science, Osaka University, Toyonaka, Osaka 560, Japan
}

(Received 27 May 1993; accepted for publication 24 February 1994)

\begin{abstract}
An experiment on an acoustic resonance spectrometer for evaluating attenuation characteristics and grain size of polycrystalline metals is described. A noncontacting electromagnetic acoustic transducer is excited to establish a shear-wave ringing in a plate sample and the amplitude spectrum is obtained by sweeping the driving if frequency through the resonances. At each resonance frequency, the sample rings down exponentially with time. The wave form is acquired to determine the time constant, or the attenuation coefficient, whose frequency dependence is finally related to the average grain size through the Rayleigh scattering theory. This nondestructive evaluation agreed with the photomicrographic examination to an accuracy of $6 \mu \mathrm{m}$ for a relatively narrow distribution of grain size in low carbon steels.
\end{abstract}

Grain size is one of the key parameters that control the mechanical properties such as yield stress and toughness of polycrystalline metals. The Hall-Petch relation states that the yield stress is inversely proportional to the square root of average grain size. Practically, the photomicrographic examination has been extensively used to date, which reveals the two-dimensional morphology on exposed cross sections. This is a destructive procedure and a nondestructive/ noncontacting means has long been waited for. A number of such techniques for the grain size determination are currently under study, relying on $\mathrm{x}$-ray diffraction, ac and dc magnetic tests, and ultrasonic attenuation.

The ultrasonic technique ${ }^{1-4}$ is the only one that can determine the through-thickness average of grain structure on which the mechanical properties depend. Spectral data are usually obtained by receiving the broadband backwall echoes in a contacting or immersion method and calculating the digitized signals with a fast Fourier transform routine. The attenuation coefficient versus frequency $f, \alpha(f)$, is fit to

$$
\alpha(f)=a f+S D^{3} f^{4}
$$

to evaluate the average grain size, $D$. This relation holds for the Rayleigh scattering region, where $D$ is much smaller than the probing wavelength. The first term gives the absorption loss associated with thermoelastic interaction, magnetic domain movement, etc. The second term represents the grain scattering. Each grain is a monocrystal and has a different crystallographic orientation from the surroundings. The elastic anisotropy makes the discontinuous acoustic impedance, causing the scattering around the grain. Corrections are indispensable to account for (a) the beam spreading during propagation and (b) the reflection loss at the sample surface loaded mechanically by the transducer (or the buffering medium). Ignorance of these effects leads to a considerable overestimation of ultrasonic attenuation.

The instrumentation and signal processing for the ultrasonic resonance spectrometer ${ }^{5-7}$ are similar to those for the pulsed nuclear magnetic resonance. 8,9 An electromagnetic acoustic transducer (EMAT) generates and receives ultrasonics without an intimate contact with the sample, because it exerts the Lorentz force in the surface skin of a conductor.
Figure 1 sketches the measurement setup. A shear-wave EMAT is excited by high power, long rf bursts gated coherently, and the thickness-shear oscillations occur in the plate samples, being free of stresses on both sides. The same EMAT receives the ringing signals (reverberations), which are processed with a superheterodyne phase sensitive detector to give the outputs of $A \cos \phi$ and $A \sin \phi$ into two channels. $A$ is the amplitude/shape factor and $\phi$ the phase; both change continuously with time. The carrier frequency $f$ has been removed through signal multiplications and filtering. Analog integration is then made for these outputs over a long gate covering the whole ringing signal after the excitation. The "amplitude spectrum" is obtained by recording the root of the sum of the squared integrator outputs at each stepped $f$.

An ultrasonic ringing is made up with a number of discrete echoes which travel across the thickness and are reflected on both surfaces. 'They are superimposed in case we use long input bursts. Because the roundtrip time is an integer multiple of the period of a resonance frequency of the sample, all the echoes are received exactly in phase when driving the EMAT at a resonance frequency. The phase $\phi$ is thus constant throughout the ringing and the integration results in a large amplitude. Away from resonance, $\phi$ varies constantly and the amplitude becomes very small owing to

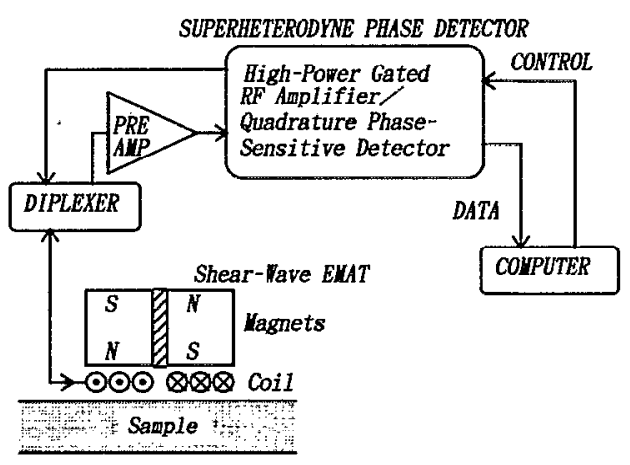

FIG. 1. Measurement system for electromagnetic acoustic resonance. 


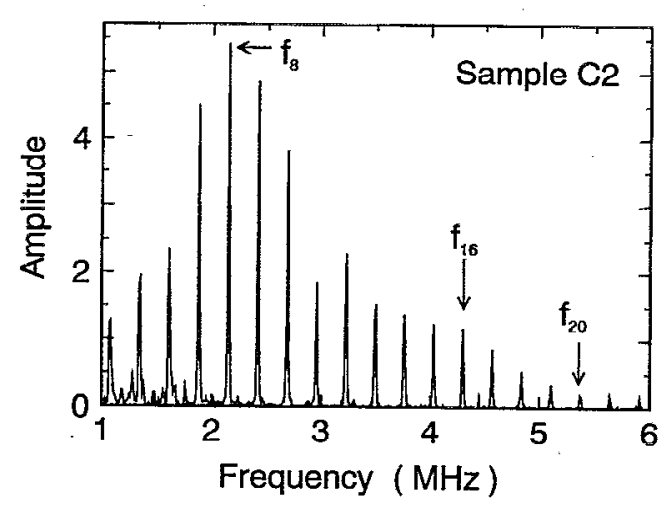

FIG. 2. Shear-wave resonance pattern on a 6-mm-thick steel plate (sample C2); $f_{n}$ is the $n$th resonance frequency.

the interference and cancellation. ${ }^{6}$ Their contrast produces sharp resonance line shapes and a high frequency resolution (in $10 \mathrm{~Hz}$ order) as displayed in Fig. 2.

Once the resonance frequencies are obtained, the attenuation coefficient can be determined at each of them. In this case, a short integrator gate is swept through the ringing signal to depict the resonant ringdown curve, to which an exponential decay, $A=A_{0} \exp (-\alpha t)$, is applied to find the time constant, $\alpha$. Figure 3 shows this procedure and Fig. 4 presents the frequency dependence. Such a result of $\alpha(f)$ is then fit to Eq. (1). Linear dependence on $f$ is now of no use: The $f^{4}$ term provides an estimate for $D$ with a suitable scattering coefficient, $S$.

We evaluated $D$ in the way outlined above and compared $D$ with the destructive inspection. Samples were low carbon steels in an annealed state. They had the size of $6 \times 100 \times 100$ $\mathrm{mm}^{3}$. They were fabricated so as to have equiaxial grains and no preferred orientation. Because of this microstructure, the samples exhibited little anisotropy in $\alpha$ and the resonance frequencies, when the shear-wave polarization was rotated over the rolling plane. The shear-wave EMAT had the aperture of $14 \times 22 \mathrm{~mm}^{2}$ and a bandwidth of $0.5-8 \mathrm{MHz}$. Typical operating parameters included the if bursts of $40 \mu$ s duration and integrator gates which were 200 and $5 \mu$ s long, respectively, for measuring the resonance frequencies and the time constants; the short gate was moved at every $1 \mu$ s. Table I

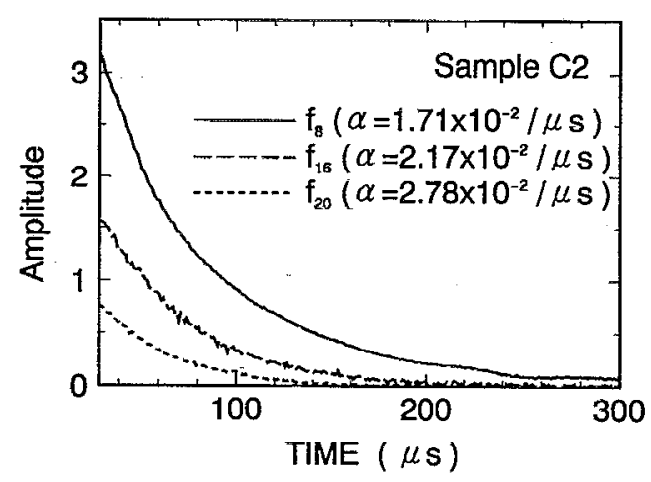

FIG. 3. Ringdown curves at three resonance frequencies indicated in Fig. 2.

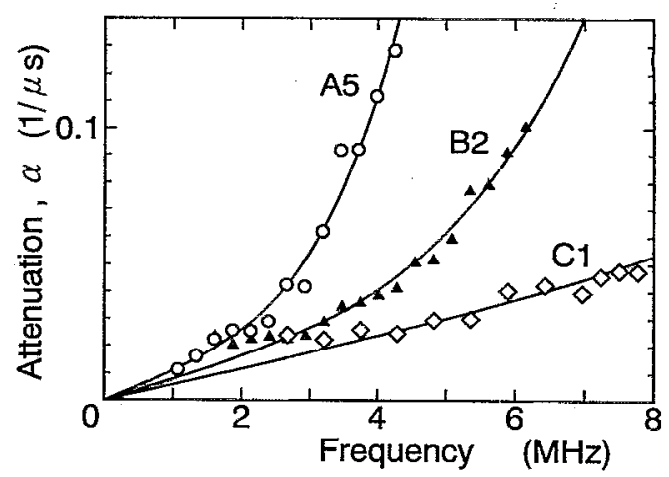

FIG. 4. Frequency dependence of attenuation coefficient (samples A5, B2, and $\mathrm{C} 1$ ). Lines are calculated from Eq. (1).

summarizes the results. We have calibrated $S$ to $S=2.17 \times 10^{-10} \mu \mathrm{s}^{3} / \mu \mathrm{m}^{3}$ using sample A1 as a reference, which differs from the theoretical value of $S=1.29 \times 10^{-10}$ $\mu \mathrm{s}^{3} / \mu \mathrm{m}^{3}$ for iron. ${ }^{1,10}$ Comparison is made against the average of the three-dimensional grain size distribution calculated from the two-dimensional data considering 12 polyhedra as the grain models. ${ }^{11}$ We observe a good overall correspondence within an error budget of $6 \mu \mathrm{m}$. But, for samples A4, A6, C3, and C4, we estimated grain sizes too large. This can be interpreted regarding the grain size distribution, since the grain scattering is characterized by $\left\langle d^{6}\right\rangle /\left\langle d^{3}\right\rangle,\langle\rangle$ being the average. ${ }^{3,12}$ These four samples possess the broad distributions of grain size, containing far larger grains than the average even if the fraction is small or has multiple peaks as shown in Fig. 5. Moreover, the maximum grain size of sample A6 $(\sim 600 \mu \mathrm{m})$ violates the hypothesis for the Rayleigh scattering. Although the results shown here were obtained in the contact experiments, this particular EMAT allowed similar attenuation measurements, except for a several percent fluctuation of $\alpha$, up to $3 \mathrm{~mm}$ lift-off from the sample surfaces.

In conclusion, the electromagnetic acoustic resonance was found to be an attractive technique to determine the

TABLE I. Comparison between the destructive and ultrasonic measurements of the average grain size of steel samples. Carbon content is A: 0.007 wt \%; B: 0.062 wt $\%$; and C: 0.147 wt $\%$.

\begin{tabular}{cccc}
\hline \hline Sample & $\begin{array}{c}\text { Destructive } \\
\text { measurement }\end{array}$ & $\begin{array}{c}\text { Ultrasonic } \\
\text { attenuation }\end{array}$ & \multicolumn{1}{c}{ Error } \\
\hline A1 & $47 \mu \mathrm{m}$ & $-(56) \mu \mathrm{m}$ & $-(9) \mu \mathrm{m}$ \\
A2 & 54 & $53(63)$ & $-1(9)$ \\
A3 & 61 & $64(76)$ & $3(15)$ \\
A4 & 76 & $86(102)$ & $10(26)$ \\
A5 & 105 & $107(127)$ & $2(22)$ \\
A6 & 205 & $292(347)$ & $87(142)$ \\
B1 & 24 & $21(25)$ & $-3(1)$ \\
B2 & 49 & $55(65)$ & $6(16)$ \\
B3 & 89 & $92(109)$ & $3(20)$ \\
B4 & 105 & $100(119)$ & $5(14)$ \\
C1 & 20 & $23(27)$ & $3(7)$ \\
C2 & 21 & $17(20)$ & $-4(-1)$ \\
C3 & 61 & $88(105)$ & $37(44)$ \\
C4 & 82 & $111(132)$ & $29(50)$ \\
\hline \hline
\end{tabular}

(): Evaluation based on the theoretical value of $S=1.29 \times 10^{-10} \mu \mathrm{s}^{3} / \mu \mathrm{m}^{3}$. 


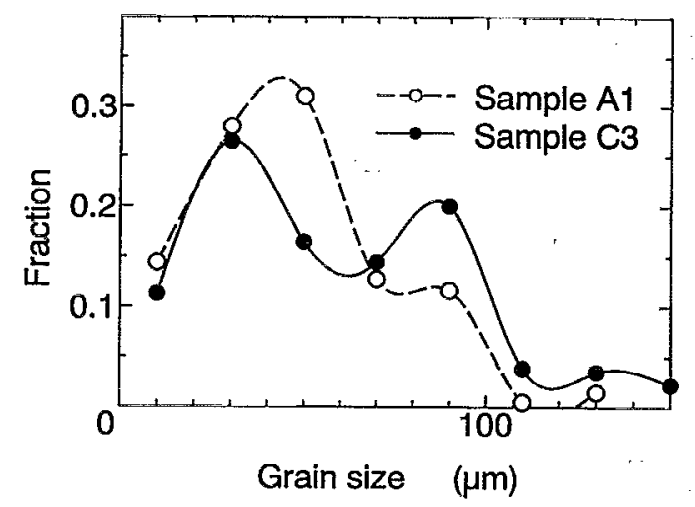

FIG. 5. Three-dimensional distribution of grain size calculated from the optical examinations.

frequency dependence of the attenuation coefficient. Corrections and calibrations are unnecessary other than $S$. Absolute determination of $\alpha(f)$ is possible. Weak coupling of EMATs excludes the losses which might otherwise occur upon reflections at the contacting surfaces. The ideally exponential decay of Fig. 3 indicates the insignificant influence of the diffraction effect. This is a consequence of using the shear wave. The value of $S$ is much larger than the longitu- dinal wave and the diffraction loss is less important if it is involved.

We are grateful to G. L. Petersen, Ritec, Inc., for stimulating discussions and suggestions during instrumentation. Samples and the two-dimensional grain size data were provided with the courtesy of the Committee of Sensors for Microstructures, Iron and Steel Institute of Japan. This work is partly supported by Grant-in-Aid No. 03555020 from the Japanese Ministry of Education.

${ }^{1}$ A. B. Bhatia and R. A. Moore, J. Acoust. Soc. Am. 31, 1140 (1959).

${ }^{2}$ R. Truell, C. Elbaum, and B. B. Chick, Ultrasonic Methods in Solid State Physics (Academic, New York, 1969).

${ }^{3}$ R. L. Smith, NDT Intern. 20, 43 (1987).

${ }^{4}$ E. P. Papadakis, in Physical Acoustics, edited by R. N. Thurston and A. D. Pierce (Academic, New York, 1988), Vol. XIX, pp. 107-155.

${ }^{5}$ D. I. Bolef and J. G. Miller, in Physical Acoustics, edited by W. P. Mason (Academic Press, New York, 1971), Vol. VIII, pp. 95-199.

${ }^{6}$ M. Hirao, H. Ogi, and H. Fukuoka, Rev. Sci. Instrum. 64, 3198 (1993).

${ }^{7}$ G. L. Petersen, C. M. Fortunko, M. Hirao, and B. B. Chick, Rev. Sci. Instrum. 65, 192 (1994).

${ }^{8}$ W. G. Clark, Rev. Sci. Instrum. 35, 316 (1964).

${ }^{9}$ A. Avogadro, G. Bonera, and M. Villa, J. Magn. Res. 35, 387 (1979).

${ }^{10}$ E. P. Papadakis, J. Acoust. Soc. Am. 37, 703 (1965).

${ }^{11}$ K. Matsuura and Y. Itoh, Mater. Trans. JIM 32, 1042 (1991).

${ }^{12}$ E. P. Papadakis, J. Appl. Phys. 35, 1586 (1964). 